\title{
A Methodological Mechanism for Applying the Hermeneutical Approach
}

\author{
Seda Gasparyan \\ Yerevan State University
}

\begin{abstract}
The present paper deals with one of the intricate problems of philology the question of reading and understanding a work of verbal creativity. The paper aims at emphasizing the methodological value of the hermeneutical approach to the study of literature which comes into being due to the presence of three basic components: imagination, language as a code between the writer and the reader, and the expected ability of the reader to share the author's emotions and thoughts. Proceeding from the basic statements of hermeneutics and Schleiermacher's theory of hermeneutical circle in particular, as well as considering the results of our former investigations we come to the conclusion that understanding verbal art is a complex process which is achieved step by step. To provide a reliable mechanism for the application of the hermeneutical approach the investigator has to take the following steps: 1) reveal the correlation of language and speech with the help of the linguostylistic method of analysis; 2) understand the aesthetic value of the work built up due to the complex relationship of the linguistic elements and the poetics of the work, which is brought out by the linguopoetic method of analysis; 3) come up to the metametasemiotic level of analysis which, in fact, belongs to the sphere of literature studies and helps reveal the intention of the author and the idea of the work.
\end{abstract}

Key words: a work of verbal creativity, understanding, interpretation, hermeneutical approach, methodological mechanism, the linguostylistic analysis, the linguopoetic analysis, metametasemiotic level. 


\section{Introduction}

This study concerns the all-important question of understanding, which has long declared itself to be one of the key problems of philology. Although we face this problem at every step of our lives - in the process of perceiving any gesture, any element of mimicry, any piece of speech - we are well aware of the fact that the essential difficulties are, first and foremost, associated with verbal creativity.

Why is it so important to refer to this ever-lasting question (ever-lasting, in fact, for it has been on the agenda of philological discussions for centuries)? First, because today, unfortunately, the number of people (especially among the younger generation) who fail to develop the ability of reading, understanding and appreciating the thesaurus of classical and contemporary literature, is increasing daily. They find it enormously difficult to read and adequately understand verbal art even in their native tongue, let alone in any of the foreign languages they study.

This unfavourable situation can be accounted for by many different reasons, some of which are objective. The first is the disposition of the human mind primarily to develop technical sciences and technologies - elements vitally important for the growth of the material basis of any society, especially in the contemporary period of human life. The second factor lies in the profound changes occurring in the cultural and spiritual values of the presentday world. But there is still another very important circumstance which cannot be ignored, and that is the fact that art in general, and verbal art is not an exception, is a highly complicated and intricate phenomenon itself (Gasparyan 2003), requiring awareness of the necessity of going deep into the essence of the work, and have our mind's ear longing for the bells that a work of art, verbal art in particular, can ring in our inner speech.

Thus, a question is bound to arise here. What is literature in fact, and how are we to approach the problem of understanding it, for if it is something that cannot be understood in the way it is meant to be, what is the use of writing it? We know that we have more or less the same problem in any other sphere of art. If, by an unfortunate chance, we suddenly faced a situation in which there 
was nobody who could, say, read musical notes or understand the harmony of colours in a piece of painting, those works of art would simply cease to exist for their addressees.

Thank God, the situation is not so grave!

However, investigations have shown that the question is still there: how do we set about the complicated process of reading, understanding and interpreting verbal art?

\section{The Basic Preconditions of Creativity}

It is common knowledge that one of the most important preconditions for the realization of any work of art is imagination. This, certainly, refers to works of fiction as well, since they present a specific field of art, in fact, a fictional reproduction of reality realized through a specific and unique use of language.

For instance, if we are to refer to the following lines taken from The

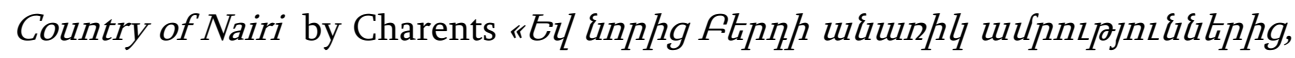

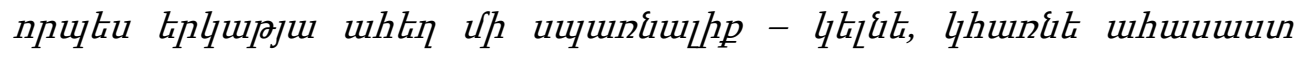

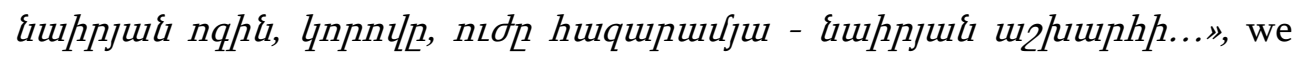
can say for sure that the image of the awakening, intensifying power lying in the basis of this context ensures dynamism, and that it is the choice and

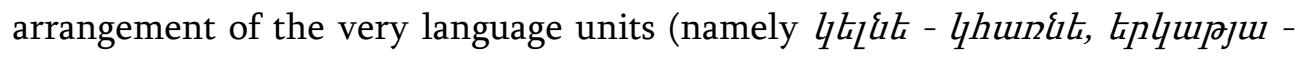

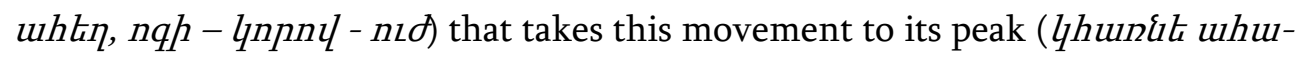
uuuun). It is due to the author's imagination and his unusual use of the language units that the context is enriched with the shades of rebirth, typical of the rebellious people of Nairi, present in other parts of the work too.

Thus, imagination and language are viewed as the most underlying and necessary elements for the realization of any work of fiction which, however, will not yield any fruits without the ability of the readers to share the emotions and feelings of the author.

If we take, say, T.S. Eliot's well known lines in his "The Love Song of Alfred Prufrock" - "Let us go then, you and I, / When the evening is spread out against the sky / Like a patient etherized upon a table" - would the reader be ever able to understand them if he/she were not endowed with the power of 
perceiving reality imaginatively, a fragment reality of which a piece of literature is a specific reverberation. When T.S. Eliot compares evening with a patient lying on the surgical table, anaesthetized, it is obvious that here we deal with a scene of reality reproduced by the author imaginatively. Will the reader be able to share the author's feelings and interpret this product of his imagination as adequately as possible, to understand the depth and subtleties of the image and appreciate its aesthetic value in this very piece of poetic work if he is unable to work his imagination into the process of understanding and if there is absolutely nothing in common between his knowledge and that of the author, i.e. if there is no "common horizon" between them (in Gadamer's terms)? This, in fact, is not one of the easiest questions to be answered straightforwardly.

Or if we look into a passage by Lawrence Durrell where the gradual appearing of the first light of the day is compared to the peeling of a fruit (the clouds peel the morning like a fruit), shall we be able to understand an original image like that, an image which is based on the comparison of absolutely incompatible phenomena (the appearing of the morning and the peeling of an exotic fruit), an image which is absolutely devoid of any conceptual coherency, if we exclude our emotional-evaluative attitude to this linguistic invention of the writer, if we "close the doors" of our imaginative perception? Surely not!

It is quite natural to admit that the borders of the imaginative perception of the reader and the author can never be the same since the differences between time, space, culture, age and sex, let alone those of personal experience are often, if not always, inevitable. Just as the author cannot create his piece of literature without having his fantasy worked into his creative process, without the ability of reprocessing the world by passing real facts through the kaleidoscope of his imagination, so the reader is unable to understand a work of literature adequately if he lacks the ability to experience objective facts imaginatively, to envisage the world creatively. However rich and manifold the reader's imagination may be, it is subjective, just as subjective as the writer's.

On the other hand, it would not be unjust to think that any text, let alone a piece of literature, is never a closed, self-contained structure, but an open 
system which avails the reader of the opportunity to introduce his understanding and his interpretation into the text.

In this connection it would be appropriate to refer to the works of $\mathrm{L}$. Shcherba, who puts forward the idea of "freedom of interpretation" (Shcherba 1957), but this is valid only to a certain extent: the freedom he speaks of is not infinite. Otherwise we should have to agree with the interpretation of a screen version of Shakespeare's "Hamlet" in which the main character is pictured as a sexual maniac.

It follows, that perception and interpretation can never be absolute. This is impossible also because imagination and the ability to share the author's feelings are rather wide and abstract notions.

All this comes to prove that even if the above-mentioned preconditions ensuring the realization of a piece of work are there, even if there exist the necessary imaginativeness and the "common horizon" establishing a close contact between the author and the reader, and the shared language code is also present, all the same, to perceive, understand and interpret a piece of literature is rather a hard task, a complex and complicated process since there are a number of other questions that are of no less importance, among them - the relation between the author and the reader, the correlation of thought and language, speech activity and communicative intention and many others.

Thus, the key to perceiving, understanding and interpreting a piece of fiction lies at the crossroads of not only linguistics and literary studies, but also other spheres of knowledge. Hence, it is not accidental that these issues have been in the focus of the thinkers' attention since ancient times, in almost all the stages of the history of literature.

\section{A Historical View of the Question of Understanding and Interpretation}

It is well known that the ancient thinkers were more attracted by the analysis of the eternal clashes between the heavenly, the earthly and their complicated interrelations, whereas the thinkers of the early medieval periods were predominantly concerned with the interpretation of theological works. The interpretation and explanation of the allegorical works dating from the late 
medieval period required even more efforts. It should be noted however that there was unfortunately no agreement in adopting these efforts. Not infrequently the above-mentioned three preconditions, as well as the personality of the writer were ignored. A literary text was examined as a phenomenon, separate from the author. However, this approach was overcome in the age of romanticism when a piece of literature was viewed as a means of expressing the self of the author, his own interpretation of reality, a means of a unique reproduction of the author's own impressions, emotions and feelings rather than a direct and "mirror reflection" of reality.

The hermeneutical approach to text interpretation was gradually taking on more significance in this very period, especially in the $18^{\text {th }}$ century when German philosophy started to examine language-related issues (Schleiermacher 1998; Dilthey 1977, 1987; Humboldt 1984, etc.). Comparative linguistics and historical investigation date back to this very period. Questions concerning the nature of language, its etymological background, as well as the historical circumstances of its formation soon appeared in the focus of linguists' attention, and the scientific achievements in the field of language studies proved preconditions for the elaboration of the theory of hermeneutics, and later also of philological hermeneutics as an approach to the study of particularly a literary text (Humboldt 1984:47): in a short period of time the key aim of this approach, which, largely speaking, was the interpretation of any piece of text, became one of the central issues of the historical and philosophical methodology of investigating texts and attached paramount importance to the study of both the external and the internal factors of the text. The form and the content of a text were soon viewed as an indivisible integrity. A lot of attention was paid to the idea of text perception as a threefold process made up of historical perception in terms of the content of the work, grammatical perception with regard to the language of the text and psychological perception aimed at considering the inner world of the given writer (Ast 1808:177):

Interestingly enough, according to von Humboldt who also regarded the role of language in a text as decisive, words did not represent the features of the physical world, but rather of the very person who spoke about that world. 
Humboldt was convinced that language helped express the inexpressible, and that was the reason why a piece of text used to give rise to so many different interpretations (Humboldt 1984:80, 392).

Sharing this viewpoint, F. Schlegel claimed that any true work of art contained numerous meanings (Schlegel 1963:81), and that the meaning of each work of fiction could be found in the diversity of possible interpretations. The concept of the close correlation of the part and the whole was considered to be the cornerstone of the theory of hermeneutics. In fact, it is of tremendous significance for the perception and understanding of any work since it is due to the constant interaction and supplementation of the parts and the whole that the piece of work is formed. Indeed, true is the idea that any piece of work is a huge net with established relations between its elements. The essence of poetic speech can be revealed by the fact that each element in it becomes relevant and necessary and is closely connected with the global whole of the work.

This statement of the interrelation of the part and the whole acquires even more importance in the context of Schleiermacher's theory of hermeneutical circle (1998) according to which, the interpreter proceeds from the intuitively perceived meaning of the whole text, then comes down to the semantic level of the text, perceives and understands the preliminary meaning of the text. i.e. the separate meanings of its elements (the parts) and goes up again and putting together the results obtained due to the analysis of the parts re-forms and reevaluates the global meaning of the work. The attention of the interpreter moves from the part to the whole through comparisons and intuition and vice versa from the whole to the part to re-interpret it. Therefore, an interpretation always calls for a re-interpretation. However, when the reader returns to the parts they are no longer the same, for they are re-perceived and re-understood through the prism of the whole. It follows, that the famous hermeneutical circle, in fact, is a hermeneutical spiral, as identified by I. Maclean (Maclean 1986). Hence, one can conclude that there can be no complete and absolutely final interpretation of any piece of text since a spiral is an endless curve and, unlike a circle, its ends never meet at any point (Spitzer 1967:35). 
In terms of the examination of the linguistic peculiarities of the text, $\mathrm{F}$. Schleiermacher's hermeneutics offered its own approach attaching a lot of importance to the perception of the meaning of not only certain words and expressions, but also their place in the whole context and in the composition of the whole work. This too proceeds from the core principle of hermeneutics, namely, understanding the text as a whole and perceiving the meaning of each word in relation with the other parts, since the meaning of words is defined in a certain context, owing to their relation with the text as a whole (Schleiermacher 1838:69).

F. Schleiermacher's hermeneutics can be considered the basis of philological hermeneutics since the idea of language is basic in his theory. $\mathrm{He}$ claims perception to be the perception of the language itself as the mentality and worldview of a person are formed and expressed through language. His approaches to subjectivity are of great interest. He regards speech as the result of the work of a separate subject. All language processes take place in the consciousness of a separate subject and despite common linguistic peculiarities, the linguistic activity is always individual. Hence, one can conclude that it is the language that is individual; language is the objective basis of the subjective speech (Schleiermacher 1998, Vossler 1905:14). F. Schleiermacher believes that perceiving means reproducing the mental processes taking place in the author's mind, of course in a reversed order. The process of the perception starts the moment you take a ready and complete piece of work and proceed towards its initial, original meaning (Schleiermacher 1838:78). Still, if it is the unconscious that prevails in the author's creative mind, the interpreter has to yield to the dominance of consciousness.

Since any idea in the text is embodied and materialized through its language, it is the linguistic concept in any piece of literary work that calls for utmost attention. However, no interpretation can be regarded complete and full if it is limited to the analysis of the language material of the text only. This is the reason why Schleiermacher in his search for maximum perception, understanding and interpretation of a text puts forward the idea of the necessity of the so called grammatical and psychological interpretations which aim at 
examining the objective and subjective concepts of a piece of text and revealing the relation between the two (Schleiermacher 1838).

Thus, we can see that the objective truth we are looking for in a piece of literature can be found in language, and only in language, which is an intermediary link between our inner world and objective reality. It is language that is capable of bringing the reader's understanding into contact with the writer's, irrespective of the time and distance between them, in fact, bridging their visions of the objective world and making the understanding of a work possible.

This, we believe, is supported by the grand idea expressed by Humboldt, who defines perception as the basic function of language and thought. He insists that the existence of language is not accounted for only by the necessity of the external, actual communication, but also by an inner demand for communication with which a human being is endowed by nature. For him the functioning of language is connected with understanding and mutual understanding, for it is the latter that accounts for the purpose of linguistic activity (Humboldt 1984).

It is known that the basic feature of any piece of speech consists in the possibility of combining linguistic elements according to the established conventions of the language, and the rules of collocation and colligation of the given language play an essential and guiding role here. Research work along these lines has already established that in a piece of imaginative writing, however constrained the latter may be by the publicly recognized norms of language, the author never confines his writing to those norms. He finds it not only possible but also necessary to use the same language material in quite an unusual way, inventing original combinations of linguistic elements, "playing" with them in order to arouse emotions in his readers, to challenge them.

When, for instance, John Galsworthy uses the metaphoric word combination "passionate dusk" in his description of a London Park in "The Forsyte Saga", or Somerset Maugham coins a combination like "ambiguous monotony" in his short story "The Force of Circumstance", it is obvious that these anomalous combinations of words have not occurred in their contexts at 
random. They carry out an aesthetic task and are also closely connected with the global purport of the works in which they are used. Thus it is the peculiar, original way in which language elements are chosen and strung together that intensifies ordinary language, introducing all kinds of deviations from its recognized norms, and it is not by chance that literature is described as a kind of writing which represents "organized violence committed on ordinary speech" (Jakobson 1956).

From what has been said it becomes clear that in a work of verbal creativity, form plays an important role in the complex correlation and unity of form and content, for it is the "how" of the literary piece that, to a great extent, guarantees the aesthetic value of a work. More than that, it is the "how" that ensures the invented, fictive nature of literature rather than the "what", for the latter never goes beyond human experience or human consciousness.

\section{Understanding as a Step by Step Process}

Following the results of our research we have arrived at the idea that owing to the importance of these general and basic concepts of the hermeneutic approach to text interpretation and considering the efficiency of the application of various methods of text analysis elaborated and effectively carried out during the last decades, it is necessary to have a certain methodological mechanism in order to achieve a possible comprehensive interpretation of a piece of literary text. We srongly believe that the complex process of perceiving, understanding and interpreting a literary text should be carried out step by step. It would not be unjust to say that the first step in cognizing a work of verbal creativity is the axiological estimation of it - evaluation that is based on the perception of the text through senses. However, investigations have shown that perception at the axiological level is impregnated with enormous difficulties and is unable to serve as safe and reliable methodological grounds for the interpretation of the work (Gasparyan 2009), at least because there can never be a one-to-one correspondence between the reader's experience and the writer's. How can the reader, who probes into the author's mind, understand and interpret his or her personal experience, private associations, feelings and impressions? Next comes 
the stage of the linguistic perception and understanding. Research has revealed that the linguistic perception can be achieved through a linguostylistic examination which is carried out on two levels - semantic and metasemiotic. At the semantic level all the possible language units that make up the text are studied as elements of the language system. On the meta-semiotic level, which does not have an expression plane of its own, the united whole of the form and content of the semantic level acts as a means to express this or that metacontent. On this level the analysis aims at revealing the stylistically coloured uses of language units, the existence of additional emotive-expressive nuances and various uses of different stylistic devices.

Thus, the method of linguostylistic analysis helps reveal the relationship between language and speech lying in the basis of any text, including a literary one. This is an important, though not a sufficient stage for the process of perception, understanding and interptetaion (Gasparyan 2008:27-35).

It is known, however, that the ultimate goal of this process, i.e. the revelation of the ideologial basis of the work, the discovery of the authorial intention cannot be achieved by a quick "jump" from the level of speech (i.e. the level of style) to the level of ideas and the global purport of the work. It follows that the researcher has to cover a long way which goes through the field of the author's poetics, to be more exact, the field of the aesthetic impact ensured by the close interaction and interplay of the composition of the work and the language used by the author. This suggests a higher level of investigation which can be realized by the application of the method of linguopoetic analysis (Gasparyan 2008:36-41).

It is however evident that both these methods - the linguostylistic method and the linguopoetic one aim at investigating the peculiar properties of the form of the literary piece. The possibly adequate understanding and interpretation calls for a united perception of both the form and the content and the authorial intention which can be be achieved through the examination of the text on the meta-meta level which is in the domain of literature studies.

We are convinced that this scheme of realizing the process of perceiving, understanding and interpreting a work of fiction is justified. On the one hand, it 
puts an emphasis of the effective cooperation of linguistics and literature studies in the field of philology, on the other hand, it ensures an accurate and sound methodological mechanism for the application of the hermeneutical approach.

We shall now try to demonstrate the linguostylistic and the linguopoetic analyses in action. As has already been mentioned, the underlying methodological basis we proceed from is that adequate understanding of a work of literature can be achieved step by step as the process of cognition of any object is a gradual one.

The first acquaintance with a work of verbal art brings the investigator to the conclusion that first and foremost it is an ordinary piece of speech just like any other speech event which is based on the dialectical unity of language and speech. To reveal this correlation of language and speech is possible, as already mentioned, by applying the method of linguostylistic analysis which starts on the semantic level, i.e. with the study of the linguistic units in their direct, nominative meanings. To begin the analysis of a text from the semantic level is particularly important when what we deal with is a piece of literature in a foreign language, for we cannot even try to appreciate the expressiveemotional-evaluative overtones present in this or that element unless we have clearly understood the direct, nominative meanings of every word, wordcombination or grammatical construction.

When we have done this, we then pass on to the metasemiotic level where the same linguistic units are studied from the point of view of their functioning in the given context.

The linguistic units can acquire a new connotative (metaphoric) content which is superimposed over their linguistic meanings proper. This "metacontent" becomes the object of investigation on the metasemiotic level.

We should hasten to add however that although the metasemiotic level is of paramount importance in a work of verbal art, it cannot be completely ignored in other varieties of human communication. It has been established, for example, that metasemiotic elements, i.e. words and word-combinations with inherent and adherent connotations, tropes and figures of speech not infrequently appear in the scientific register as well. The use of these elements 
in an informative text is accounted for by the great wish of the author to sometimes look extraordinary, sometimes express his attitude towards the subject he has chosen to speak about. Overstepping of the stylistically neutral, informative narration very often appears when the author tends to clarify his point of view and convince his readers in the righteousness of his approach to the problem or stand out in defense of his doctrine.

On the other hand, in works of verbal art we may come across different informative insertions which acquire a specific value under the influence of the general purport of the given literary work. For an example of a kind of intertwinement of the aesthetic and the informative functions of speech in a work of verbal art one may be referred to Hemingway's writings, say "The Old Man and the Sea" where there are quite a number of encyclopedic, informative words and word-combinations, even some terms and terminological combinations particularly in the description of the shark. These elements are, certainly, not included in his text to give the reader exact and detailed information on how the shark looked, but to convey the idea about how devoted to the sea the old man was and indicate the profundity of his knowledge of the sea.

If we take these statements for granted, it will be justified to conclude that whatever the text, it is based on the dialectical correlation and unity of semantics and metasemiotics which can be revealed with the help of the linguostylistic method of analysis. This method is universal and can be applied to any kind of text irrespective of its register.

When we turn to imaginative writing, particularly to a piece of verbal art, we face a completely different picture, for here what we are after is the general intention of the writer and the aesthetic content he tries to convey to his readers. In this case we cannot confine our study to linguostylistic analysis only. It is only a preliminary step in our attempt to perceive a piece of verbal art as a global artistic whole. It is here that to make the next step towards possibly complete and adequate understanding of a work of literature we turn to the linguopoetic analysis which is aimed at revealing the complex correlation of the verbal texture of the given work and its composition which results in a certain 
aesthetic impact. The linguopoetic analysis is applicable only to verbal art. In this case the investigation of a work begins from "above", i.e. from understanding the general purport of the work towards the study of the verbal texture.

In other words, linguopoetics deals with the complex correlation of the language and poetics of the work of verbal creativity. To be more exact, this method aims to reveal the sum total of different linguistic means with the help of which the writer's intention is conveyed and the aesthetic effect is achieved. It is an important step towards the hermeneutical interpretation of a literary work.

Now let's look into the text:

On Saturday, October 5, the sky had been blue all day deepened after sunset to the bloom of grapes. There was no moon, and a clear dark, like some velvety garment, was wrapped around the trees, whose thinned branches, resembling plumes, stirred not in the still, warm air. All London had poured into the park, draining the cup of summer to its dregs.

Couple after couple, from every gate, they streamed along the paths and over the burnt grass, and one after another, silently out of the lighted spaces, stole into the shelter of the feathery trees, where, blotted against some trunk, or under the shadow of shrubs, they were lost to all but themselves in the heart of the soft darkness.

To fresh-comers along the paths, these forerunners formed but part of that passionate dusk, whence only a strange murmur, like the confused beating of hearts, came forth. But when that murmur reached each couple in the lamp-light their voices wavered, and ceased, their arms enlaced, their eyes began seeking searching probing the blackness. Suddenly, as though drawn by invisible hands, they, too, stepped over the 
railing, and silent as shadows, were gone from the light.

The stillness, enclosed in the far, inexorable roar of the town, was alive with the myriad passions, hopes, and lives of multitudes of struggling human atoms; for in spite of the disapproval of that great body of Forsytes, the Municipal Council - to whom love had long been considered, next to the Sewage Questions, the gravest danger to the community - a process was going on that night in the Park, and in a hundred other parks, without which the thousand factories, churches, shops, taxes, and drains, of which they were custodians, were as arteries without blood, a man without a heart.

The instincts of self-forgetfulness, of passion, and of love, hiding under the trees, away from the trustees of their remorseless enemy, the "sense of property", were holding a stealthy revel, and Soames, returning from Bayswater - for he had been alone to dine at Timothy's - walking home along the water, with his mind upon that coming lawsuit, had the blood driven from his heart by a low laugh and the sound of kisses. He thought of writing to the Times the next morning, to draw the attention of the Editor to the condition of our parks. He did not, however, for he had a horror of seeing his name in print".

(Galsworthy 2001:193-194)

Starting our linguostylistic analysis of the text we look up words like

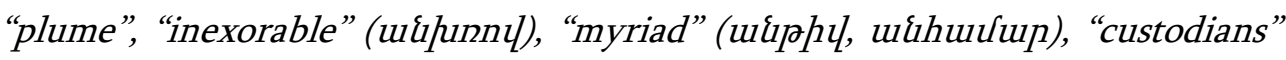

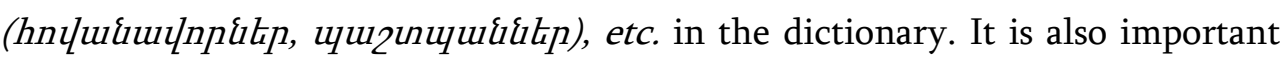
to understand the difference between "seek" and "search", "dark" and "darkness", etc.

After this the stylistic differences between different words should be established, for side by side with stylistically neutral words like "Saturday", "sky", 
"blue", "sunset", etc. there are also emotionally coloured ones in the text such as "clear", "velvet”, "soft”, "passionate”, "danger", “disapproval”, "remorseless”, etc. The word "whence" deserves attention because it is an archaic one. The highflown word "multitude" and the bookish element "inexorable" add to the stylistic atmosphere of the text. It should also be noted that there are semantically close words in the extract such as "love"-"passion"; "soft""velvety"; "seek"-"search"; as well as antonymous pairs like "light"- "darkness".

The words "fresh-comers" and "forerunners" are interesting from the point of view of their morphological structure. If the latter can be found in the dictionary in the meaning of "predecessor", in the case of "fresh-comer" which is an occasional coinage, the meaning may be derived from the meaning of its components.

The semantic analysis on the level of minor syntax shows that the number of attributive word-combinations (purple grapes, clear dark, velvety garment, still, warm air) is prevailing, whereas further on we come across predicative constructions (murmur reached; voices wavered and ceased; arms enlaced; etc.). There is also an idiom proper in the text (to drain sth. to its dregs).

The study of the major syntax shows that the majority of sentences in the passage are long, compound sentences with a lot of homogeneous parts. There are some parenthetical insertions like "however"; "for he had been alone to dine at Timothy's"; etc., the role of which is decisive in the prosodic organization of some parts of the passage.

Passing on to the metasemiotic level, we shall now try to see what additional content is acquired by the linguistic units in the context of the extract. Our attention is immediately attracted by the metaphoric wordcombinations like "passionate dusk", "soft darkness", "feathery trees" with the help of which the mysterious, romantic atmosphere of the night park is created. In the word-combination "clear dark" two completely incompatible words are brought together which results in an oxymoron. Besides the mentioned devices the writer also makes use of other tropes, such as personification as in "instincts of self-forgetfulness ... were holding a stealthy revel", and metonymy as in "all London had poured into the Park". 
Being a skillful master of deforming idiomatic expressions here as well Galsworthy presents the idiom "drain sth. to its dregs" as "drains the cup of summer to its dregs" thus reviving it. The word "cup" used metaphorically is usually associated with "bitterness", "sorrow", etc. But here its combination with the word "summer" endows the idiomatic expression with positive connotations.

The word "love" is very unusually used in the passage in plural, perhaps in the analogy with "passions" and "hopes".

There are quite a few figures of speech which appear in the context with very little changes: lexical repetitions (a process was going on that night in the Park, and in a hundred other parks; myriad passions, hopes, and lives of multitudes of struggling human atoms; the instincts of self-forgetfulness, of passion, and of love) and parallel constructions (were as arteries without blood, a man without a heart).

The best effect of the use of semantically close words is achieved in the socalled synonymic condensation in the line "their eyes began seeking searching probing the blackness".

It is not difficult to notice that almost all the stylistic devices are concentrated in the first three paragraphs where the lovers in the night park are described. In the last two paragraphs which presents Soames' pondering over what was going on, on the contrary, the number of ready-made phrases ("had long been considered", "to draw the attention of", "in print", "the next morning”, etc.), usually characteristic of an informative and everyday speech, increases. In this part of the extract we also find words (process, lawsuit, condition of our parks, Municipal Council, Sewage Question, etc.) more appropriate for a businessman's speech rather than for a poetic description.

Thus, the analysis presented shows the mechanism of the linguostylistic analysis. But it is not difficult to see that, however detailed and scrupulous it may be, it merely acquaints us with the text of the extract without revealing its aesthetic value. This, in fact, is the task of the linguopoetic analysis which first and foremost begins with identifying the place and role of the extract in the 
context of the whole novel and then develops, all the time modifying the investigator's understanding of its parts.

Our research has shown that throughout the novel Galsworthy opposes two ways of perceiving the world, or rather two attitudes to life. One of them is characteristic of the Forsytes and the like and is described in the novel as "the sense of property", whereas the other is based on the ideals of beauty and love embodied by Irene and Bossinie in the novel. In the presented extract this opposition can be traced on all the levels. In this sense the role of the extract is indispensible in revealing the real purport of the novel.

The first half of the text, i.e. paragraphs from 1 to 3 must be clearly kept apart from the second one (paragraphs $4 \& 5$ ) as far as the rhythmic, phonetic and timbral characteristics are concerned.

This poetic description requires an appropriate, "lyrical" timbre which is characterized by a decreased volume of voice, breathiness and slowing down of the tempo in such elements as "velvety garment", "still, warm air"; "passionate dusk". The fact that the author feels sympathetic about what is going on in the dark of the park is borne out not only by the prosody but also the specific balanced rhythm achieved by the repetitions in the first three paragraphs ("their voices wavered and ceased, their arms enlaced, their eyes began seeking searching probing ..."), also the parallel constructions ("couple after couple"; "one after another") and by the alliteration of the stressed and unstressed syllables ("couple after couple, from every gate, they streamed along the paths and blotted against some trunk, or under the shadow of shrubs"). The alliterations and the assonances in "blue-bloom-moon; shadow of shrubs; heartdark-darkness-park" add to the rhythmical unity of the extract.

In paragraph 4 where the author arrives at certain conclusions against the general poetic background of the narration some elements of facetious intonation are introduced. The author mocks the Forsytes who think that love, next to the Sewage Question, is the gravest danger to the community.

At the end of the passage the solemn tone is substituted for a neutral one because Soames appears and the emotionality of the narrative gives way to the businesslike manner. However the author's voice does not submerge in Soames' 
voice and hardly notable irony creeps in (he thought of writing to the Times the next morning, to draw the attention of the Editor to the condition of our parks).

The strength of the aesthetic impact of this extract consists in the fact that the author does not simply inform of the existence of the opposing attitudes towards life, but makes the reader feel the contradiction with the help of the specific choice and arrangement of words, stylistic devices and particularly by means of the change in the tone of the narration.

\section{Conclusion}

Thus, we can conclude that the linguostylistic and liguopoetic analyses are completely different from the point of view of their ontology. However, as far as the study of a work of verbal art is concerned, they appear to be very closely interconnected. The linguopoetic analysis is based on the results of the linguostylistic one and usually follows it. The linguopoetic analysis depends, to a great extent, on the background knowledge and the intuition of the reader. It necessarily includes the analysis of the prosodic features of the text, for a philological perception of a work of literature is impossible without hearing the "bell" it rings in the inner speech of the reader.

\section{References:}

1. Ast, F. (1808) Grundlinien der Grammatik, Hermeneutik und Kritik. Landshut, Germany: Jose.

2. Dilthey, W. (1977) Descriptive Psychology and Historical Understanding. The Hague: Springer Netherlands.

3. Dilthey, W. (1987) Vvedenie v nauki o dukhe. // Zarubezhnaya estetika i teoriya literatury $X I X i X X v V$. (Traktaty, statyi, esse). M.: MSU Press.

4. Gasparyan, S. (2003) Concerning the Problem of Understanding Verbal Art. // Gitelik, №10, Yerevan.

5. Gasparyan, S. (2008) Linguopoetika obraznogo sravneniya. Yerevan: Lusakn. 
6. Gasparyan, S. (2009) The Recreation of Symbolic Images in Literature. // In Search of (Non)Sense. / Ed. by E. Chrzanowska-Kluczewska, G. Szpila. Newcastle upon Tyne: Cambridge Scholars Publ.

7. Humboldt, W. (1984) Izbrannye Trudy po yazykoznaniyu. M.: Progress.

8. Jakobson, R. (1956) Two Aspects of Language and Two Types of Aphasic Disturbances. // Jakobson R. and Halle M. Fundamentals of Language. The Hague: Mouton \& Co. Printers.

9. Maclean, I. (1986) Reading and Interpretation. // A. Jefferson and D. Robey (eds.) Modern Literary Theory: A Comparative Introduction. London: B. T. Batsford, pp.122-144.

10. Shcherba L. V. (1957) Izbrannye raboty po russkomu yazyku. Moscow: Uchpedgiz.

11. Schlegel, A.W. (1963) Kritische Schriften und Briefe. Stuttgard: Kohlhammer.

12. Schleiermacher, F. (1838) Hermeneutik und Kritik mit besonderer Beziehung auf das Neue Testament. Berlin: Reimer.

13. Schleiermacher, F. (1998) Hermeneutics and Criticism and Other Writings. Cambridge: CUP.

14. Spitzer, L. (1967) Linguistics and Literary History. Essays in Stylistics. New York: Princeton Legacy Library.

\section{Source of Data:}

1. Galsworthy, J. (2001) The Man of Property. // The Forsyte Saga. Vol. 1, part 3. UK, Kent: Mackays of Chatham plc.

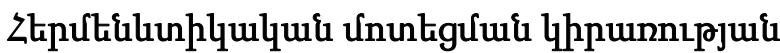

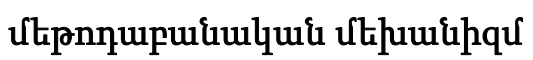

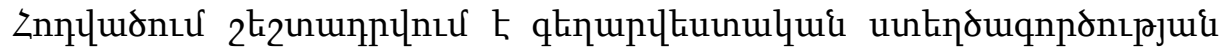

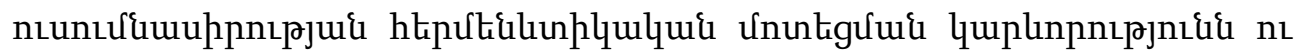

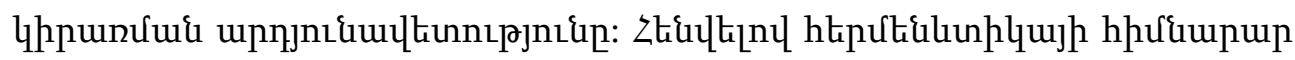

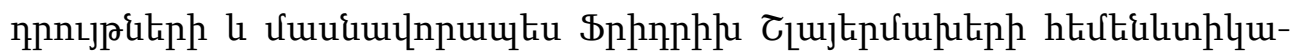




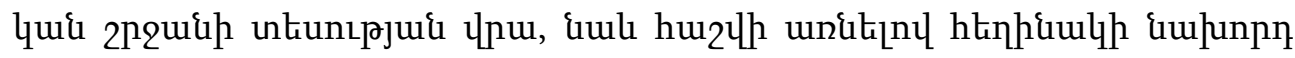

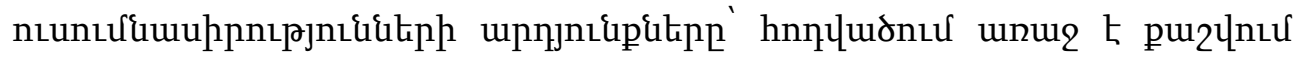

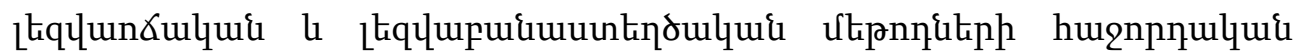

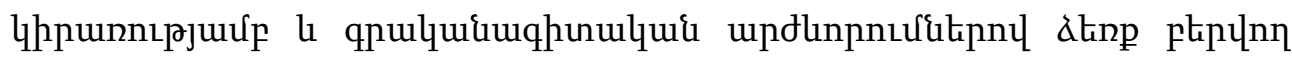

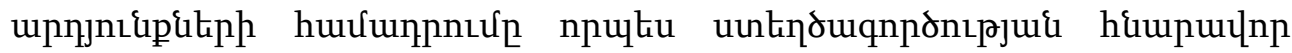

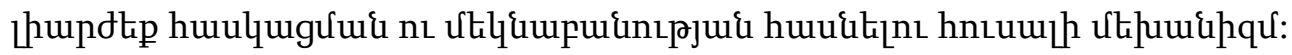

Received by the Editorial Board 12.12.2018

Recommended for publication by the reviewers 22.03.2019

Accepted for print 22.04.2019 